\title{
Parotis Kitlelerinde Klinik Deneyimimiz: Kitle Boyutu ile İnce İğne Biyopsi Sonuçları Arasındaki İlişki
}

\section{Our Clinical Experiences in Parotid Masses: The Relationship Between the Size of Parotid Masses and the Results of Fine Needle Aspiration Biopsy}

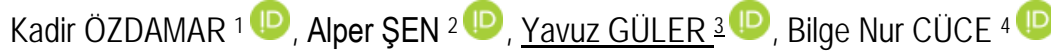

\author{
1 Özel Lotus Hastanesi Kulak Burun ve Boğaz Hastalıkları Bölümü, Şanlıurfa \\ 2 Harran Üniversitesi Tıp Fakültesi Kulak Burun ve Boğaz Hastalıkları Anabilim Dalı, Şanlıurfa \\ 3 Balıklıgöl Devlet Hastanesi Kulak Burun ve Boğaz Hastalıkları Bölümü, Şanlıurfa \\ 4 Meram Üniversitesi Tıp Fakültesi Çocuk Hastalıkları Anabilim Dalı, Konya
}

Öz.

Amaç: Parotis kitle boyutu ile ince iğne aspirasyon biyopsi (IIAB) sonuçları arasındaki ilişkiyi değerlendirmek. Materyal ve Metod: Bu çalışmaya parotis bezinde kitle nedeniyle preoperatif IİAB yapılan 56 olgu (25 erkek 31 kadın; ortalama yaş $43.0 \pm 11,2$ yll, aralık: 13-82) dahil edildi. Tüm olgulara tam bir kulak burun boğaz muayenesi yapıldıktan sonra, parotis iliAB yapıldı. Tüm olgular kitle boyutuna göre, $2 \mathrm{~cm}$ 'den küçük, $2-4 \mathrm{~cm}$ arasında olanlar ve 4 cm'den büyük olanlar olmak üzere üç gruba ayrıldı. Kitle boyutuna göre lïAB nin duyarlıık, özgüllük,doğruluk, pozitif öngörü ve negatif öngörü değerleri değerlendirildi.

Bulgular: Parotis kitleleri için İ̈AB 'nin duyarlıığı \%60, özgüllüğü \%95,5, doğruluk \%81, pozitif öngörü değeri \%90 ve negatif öngörü değeri $\% 77,8$ idi. Kitle boyutu $2 \mathrm{~cm}$ 'den küçük olanlar için duyarllık $\% 50$, özgüllük $\% 88,9$, doğruluk \%76,9, pozitif öngörü değeri \%66,7 ve negatif öngörü değeri \%80 idi. Kitle boyutu $2-4 \mathrm{~cm}$ arasında olanlar için duyarlılık $\% 50$, özgüllük $\% 100$, doğruluk $\% 83,3$, pozitif öngörü değeri $\% 100$ ve negatif öngörü değeri $\% 80$ idi. Kitle boyutu $4 \mathrm{~cm}$ 'den büyük olanlar için duyarllık \%80, özgüllük \%100, doğruluk \%83,3, pozitif öngörü değeri \%100 ve negatif öngörü değeri \%50 idi.

Sonuç: Bu çalışmada, parotis kitle boyutu ile IïAB test sonuçları arasındaki ilişki değerlendirildi. Parotis kitle boyutu arttıkça, iliAB test sonuçlarının duyarlılık ve özgüllüğünün artı̆̆ı saptandı.

Anahtar Kelimeler: Parotis tümörü, Boyut, İnce iğne aspirasyon biyopsisi, Duyarlılık

Abstract

Background: To evaluate the relationship between the size of parotid gland masses and the results of fine needle aspiration biopsy (FNAB).

Materials and Methods: In total, 56 patients (25 males 31 females; average age, $43.0 \pm 11.2$ years;age range:13-82 years) with parotid gland mass who underwent preoperative FNAB were included in this study. All patients underwent parotid FNAB following clinical examination. All patients were divided into three groups in terms of the size of parotid gland mass; $<2 \mathrm{~cm}, 2-4 \mathrm{~cm}$ and $>4 \mathrm{~cm}$. The sensitivity, specifity, the diagnostic accuracy, positive predictive value (PPV) and negative predictive value (NPV) of FNAB were evaluated according to the size of mass.

Results: The sensitivity, specificity, overall accuracy, PPV and NPV rates of FNAB for parotid masses were $60 \%$, $95.5 \%, 81.0 \%, 90.0 \%$ and $77.8 \%$, respectively. For parotid mass with a size smaller than $2 \mathrm{~cm}$, the sensitivity, specificity, overall accuracy, PPV and NPV rates of FNAB were $50 \%, \% 88.9 \%, 76.9 \%, 66.7 \%$ and $80 \%$, respectively. For parotid mass with a size between $2-4 \mathrm{~cm}$, these rates were $50 \%, 100 \%, 83.3 \%, 100 \%$ and $80 \%$, respectively. For parotid mass with a size bigger than $4 \mathrm{~cm}, 80 \%, 100 \%, 83.3 \%, 100 \%$ and $50 \%$, respectively. Conclusion: In the present study, we evaluated the relationship between the size of parotid gland mass and the results of FNAB. It was observed that the sensitivity and specificity of FNAB test increased as the parotid mass size increased.

Key words: Parotid neoplasm, Size, Fine needle aspiration biopsy, Sensitivity
Sorumlu Yazar I

Corresponding Author

Dr. Yavuz GÜLER

Balıklıgöl Devlet Hastanesi Kulak Burun ve Boğaz Hastalıkları Bölümü, Şanlıurfa

e-mail: dryavuzguler@hotmail.com

Tel: +905446500750

Geliş tarihi / Received: 13.07.2020

Kabul tarihi / Accepted: 10.08.2020

DOI: 10.35440/hutfd.768541 


\section{Giriş}

Tükürük bezi sistemi, vücutta büyük ve küçük birçok tükürük bezinden oluşmaktadır. Parotis, submandibuler ve sublingual bezler major tükürük bezleri olarak kabul edilirken, oral kavite, dil, dil kökü, nazofarenks, yumuşak ve sert damak submukozasında yerleşmiş çok sayıda minör tükürük bezi bulunmaktadır (1). Tükürük bezi tümörleri, baş boyun tümörlerinin sadece \%2-3 ' ünü oluşturmaktadır (2). Bu tümörler, tükürük bezlerinin bulunduğu her alanda görülebilmesine rağmen, en sık olarak parotis bezinde görülmektedir (3). Literatürde, tanımlanmış çok sayıda histopatolojik tükürük bezi tümörü bulunmaktadır. En sık görülen benign tümör pleomorfik adenom iken, en sık görülen malign tümör mukoepidermoid karsinomdur $(4,5)$. Tükürük bezi tümörlerinin çoğunluğu, klinik bulgu vermeden yavaş büyüyen kitleler olarak ortaya çıkmaktadır. Bu tümörlerin, klinik semptom vermeden yavaş büyümeleri olguların hekime başvurmasını geciktirmektedir. Abrams ve Finck (2) tarafindan sunulan bir sialoadenoma papilliferum olgusunda, olgunun kitleyi fark edip hekime başvurması arasında geçen sürenin yaklaşık 10 ile 12 yıl arasında değiştiğini bildirmiştir.

Tükürük bezi tümörlerinin yönetimi, cerrahlar arasında farklılık göstermektedir. Literatürde bu konuda kabul edilmiş bir tıbbi rehber bulunmamaktadır. Parotis kitlelerindeki malignite şüphesi, klinik korelasyon ile olgunun anamnezi arasındaki korelasyona dayanmaktadır (3). Birçok tanısal test bulunmakla birlikte, hiçbir tanısal testin sonucu kesin değildir. En sık kullanılan tanısal test, ince iğne aspirasyon biyopsisi (IIAAB)'dir (4-8). IIIAB, daha çok tiroid nodülü ve boyun kitlelerinin tanısında kullanılırken, son zamanlarda parotis kitlelerinin tanısında da kullanılır hale gelmiştir. iliAB 'nin poliklinik şartlarında kolay ve güvenilir şekilde yapılabilmesi, işlem öncesinde anesteziye ihtiyaç duyulmaması, hızlı sonuç alınabilmesi ve nispeten kabul edilebilir düzeyde doğru tanı koyması, testin kullanımını artırmıştır (911). Parotis kitlelerinde IIAB 'nin kullanımı konusunda farklı görüşler bulunmaktadır. Batsakis ve ark. (12) parotis kitlelerinde preoperatif IİAB yapılmasının çoğu hasta için gereksiz olduğunu bildirmiştir.

Literatürde, parotis kitle boyutu ile IİAB sonuçları arasındaki ilişkisini araştıran çok az sayıda çalışma bulunmaktadır. Bu çalışmada, parotis kitle boyutu ile IIIAB test özellikleri arasındaki ilişki değerlendirildi.

\section{Materyal ve Metod}

Bu retrospektif klinik çalışma, Ocak 2015 ile Aralık 2017 tarihleri arasında hastanemiz kulak burun boğaz hastalıkları kliniğinde parotis bezinde kitle nedeniyle opere edilen 56 olgu (25 erkek 31 kadın; ort.yas $43.0 \pm 11.2$ yıl, aralık: 13-82) ile yapıldı. Çalışma Harran Üniversitesi Tıp Fakültesi Etik Kurulu tarafından onaylandı (Etik kurul no:18/01/04). Çalışmaya katılan tüm hastalardan bilgilendirilmiş onam formu alındı. Çalışma Helsinki Deklarasyonu ilkeleri ve lyi klinik uygulamalar kılavuzuna uygun olarak gerçekleştirildi.

Hastaların demografik bilgilerine hastane kayıt sistemindeki dosyaları taranarak ulaşıldı. Tüm olgulara tam bir kulak burun boğaz muayenesi yapıldıktan sonra, parotis ultrasonografik (USG) ve parotis MR görüntüleme istendi. Parotis USG ve MRI görüntülerine göre yüzeyel ve derin lob ayrımı yapılarak kitle saptanan tüm olgulara poliklinik şartlarında, lokal anestezik madde enjeksiyonun ardından, 23 gauge $(0.57 \mathrm{~mm})$ iğne ile IIIAB yapıldı. IİAB kitleye tek bir noktadan 45 derecelik açıyla girilerek yapıldı. Elde edilen patolojik materyaller en az 3-4 adet lama püskürtüldükten sonra alkol içinde fiksasyonu sağlanarak patoloji laboratuarına gönderildi. IIIAB sonucuna göre olgular benign, şüpheli malign, malign ve non-diagnostik olarak değerlendirildi. Tüm olgular IIIAB sonucuna göre bilgilendirildi ve olgulardan cerrahi için onam alındıktan sonra ameliyat edildi. Tüm patolojik materyaller histopatolojik incelemeye gönderildi. Tüm olgular kitle boyutuna göre, $2 \mathrm{~cm}$ 'den küçük, 2-4 $\mathrm{cm}$ arasında ve $4 \mathrm{~cm}$ 'den büyük olmak üzere üç gruba ayrıldı. Kitle boyutuna göre IIIAB 'nin duyarlılık, özgüllük, pozitif öngörü (PÖD) ve negatif öngörü değerleri (NÖD) değerlendirildi.

İstatistiksel İncelemeler

İstatistiksel analizler için Windows Statistical package for Social Science (SPSS) 13.0 (SPSS inc., Chicago, ABD) bilgisayar programı kullanıldı. Çalışma verileri değerlendirilirken tanımlayıcı istatistiksel metodlarda ortalama, standart sapma, medyan, frekans, oran, minimum, maksimum kulanıldı.

\section{Bulgular}

Olguların 41 'ine (\%73.2) süperfisial parotidektomi uygulanırken, 15 olguya (\%17.8) total parotidektomi uygulandı. Parotis kitleleri 16 olguda (\%28.5) sağ tarafta saptanırken, 40 olguda (\%71.5) ise sol tarafta saptandı. Parotis IIIAB sonuçları tablo 1 'de özetlenmiş̧ir.

Tablo 1. Parotis İnce Iğne Aspirasyon Biyopsi Sonuçları

\begin{tabular}{|l|l|}
\hline Parotis IIAB sonucu & Sayı (\%) \\
\hline Pleomorfik adenom & $4(\% 7.1)$ \\
\hline Warthin tümörü & $3(\% 5.4)$ \\
\hline $\begin{array}{l}\text { Diğer benign sitopatolojik bulgular( kronik enflamasyon, lenf } \\
\text { nodu hiperplazisi, kistik lezyon) }\end{array}$ & $23(\% 41.0)$ \\
\hline Non-diagnostik & $19(\% 33.9)$ \\
\hline Malignite şüpheli lezyon & $6(\% 10.8)$ \\
\hline Mukoepidermoid karsinom & $1(\% 1.8)$ \\
\hline Toplam & $56(\% 100)$ \\
\hline
\end{tabular}

İ̈AB; Ince lğne Aspirasyon Biyopsisi

Histopatolojik sonuçlar tablo 2 'de özetlenmiştir. Histopatolojik sonuçlar ile iliAB arasındaki korelasyon tablo 3 'de özetlenmiştir. Histopatolojik sonuçlar, kitle boyutuna göre değerlendirildiğinde 19 olguda (\%33.9) $2 \mathrm{~cm}$ 'in altında, 34 olguda (\%60.7) $2-4 \mathrm{~cm}$ arasında ve 7 olguda 
(\%5.4) 4 cm 'den büyük idi (Tablo 4).

Tablo 2. Postoperatif histopatolojik sonuçlar

\begin{tabular}{|l|l|}
\hline Postoperatif histopatolojik sonuçlar & Sayı (\%) \\
\hline Pleomorfik adenom & $19(\% 33.9)$ \\
\hline Warthin tümörü & $10(\% 17.9)$ \\
\hline $\begin{array}{l}\text { Diğer benign sitopatolojik bulgular( kronik enflamasyon, lenf nodu hi- } \\
\text { perplazisi, kistik lezyon) }\end{array}$ & $19(\% 33.9)$ \\
\hline Mukoepidermoid karsinom & $4(\% 7.1)$ \\
\hline Adenoid kistik karsinom & $1(\% 1.8)$ \\
\hline Non-hodgkin lenfoma & $1(\% 1.8)$ \\
\hline Leomyosarkom & $1(\% 1.8)$ \\
\hline Adenokarsinom & $1(\% 1.8)$ \\
\hline Toplam & $56(\% 100)$ \\
\hline
\end{tabular}

Tablo 3. Parotis kitlelerinde ince iğne aspirasyon biyopsisi ve histopatolojik sonuçların karşılaştırılması

\begin{tabular}{|l|l|l|l|l|l|}
\hline \multicolumn{7}{|c|}{ Histopatolojik sonuçlar } \\
\hline $\begin{array}{l}\text { Ince iğne aspi- } \\
\text { rasyon biyop- } \\
\text { sisi }\end{array}$ & $\begin{array}{l}\text { Whar- } \\
\text { tin Ade- } \\
\text { nom }\end{array}$ & $\begin{array}{l}\text { Pleomorfik } \\
\text { Adenom }\end{array}$ & $\begin{array}{l}\text { Diğer } \\
\text { bening } \\
\text { tümör }\end{array}$ & $\begin{array}{l}\text { Malign } \\
\text { lezyonlar }\end{array}$ & Toplam \\
\hline $\begin{array}{l}\text { Pleomorfik ade- } \\
\text { noma }\end{array}$ & 3 & 0 & 0 & 1 & 4 \\
\hline Whartin tümör & 0 & 3 & 0 & 0 & 3 \\
\hline $\begin{array}{l}\text { Diğer benign lez- } \\
\text { yonlar }\end{array}$ & 6 & 4 & 12 & 1 & 23 \\
\hline $\begin{array}{l}\text { Non-diagnostik } \\
\text { Şüpheli malignite }\end{array}$ & 0 & 30 & 6 & 0 & 19 \\
\hline Malign tümörler & 0 & 0 & 1 & 5 & 6 \\
\hline Toplam & 19 & 10 & 19 & 8 & 56 \\
\hline
\end{tabular}

Tablo 4. Parotis kitlesi boyutuna göre ince iğne aspirasyon biyopsisinin histopatolojik sonuçlarla uyumunun değerlendirilmesi

\begin{tabular}{|c|c|}
\hline Kitle boyutu & İnce iğne aspirasyon biyopsisi \\
\hline $0<\leq 2 \mathrm{~cm}$ & $\begin{array}{l}\text { *18 olgunun IIIAB ile histopatolojik sonuç karşılaştırması } \\
\text { - } 6 \text { olguda sonuçlar uyumlu, } \\
-12 \text { olguda sonuçlar uyumsuz }\end{array}$ \\
\hline $2<\leq 4 \mathrm{~cm}$ & $\begin{array}{l}\text { * } 30 \text { olgunun IïAB ile histopatolojik sonuç karşılaştırması, } \\
\text {-13 olguda sonuçlar uyumlu, } \\
\text {-17 olguda sonuçlar uyumsuz }\end{array}$ \\
\hline$>4 \mathrm{~cm}$ & $\begin{array}{l}\text { *7 olgunun IİAB ile histopatolojik sonuç karşıllaştırması } \\
\text { - } 5 \text { olguda sonuçlar uyumlu, } \\
-2 \text { olguda sonuçlar uyumsuz. }\end{array}$ \\
\hline
\end{tabular}

Parotis kitleleri için İ̈AB 'nin duyarlılı̆ı $\% 60$, özgüllüğü $\% 95.5$, doğruluk \%81, PÖD \%90 ve NÖD \%77.8 idi. Kitle boyutu $2 \mathrm{~cm}$ 'den küçük olanlar için duyarlılık \%50, özgüllük \%88.9, doğruluk \%76.9, PÖD \%66.7 ve NÖD \%80 idi. Kitle boyutu $2-4 \mathrm{~cm}$ arasında olanlar için duyarlılık $\% 50$, özgüllük \%100, doğruluk $\% 83.3$, PÖD $\% 100$ ve NÖD $\% 80$ idi. Kitle boyutu $4 \mathrm{~cm}$ 'den büyük olanlar için duyarlıık $\% 80$, özgüllük $\% 100$, doğruluk $\% 83.3$, PÖD $\% 100$ ve NÖD $\% 50$ idi (Tablo 5).

\section{Tartışma}

IİAB ucuz, güvenli, uygulaması kolay, nispeten ağrısız ve minimal komplikasyonları olan tanısal bir testtir (13-15). Parotis kitlelerinde kullanımı konusunda literatürde henüz bir görüş birliği bulunmamaktadır. Çoğu cerrah, ameliyat planını yaparken IIIAB sonuçlarını göz önüne almadığını bildirmektedir $(16,17)$. Parotis kitlelerinin yönetiminde IİAB 'nin yapılması gerektiğini bazı cerrahlar savunurken, bazıları İंAB 'ye gerek olmadığını savunmaktadır (18-20). Parotis kitlelerinde IIIAB yapılmasının temel amacı malign bir tümörün benign bir tümörden ayrımını yapmaktır. IIIAB ile tümörün histolojik tipi konusunda bilgi sahibi olunması, yapılacak cerrahi işlemin önceden planlanmasına katkı sağlayacaktır. Dünya Sağlık Örgütü'nün 2005 yılındaki parotis tümörleri sınıflamasında, 25 'den fazla malign tümör tariflenirken, sadece 9 benign tümör tariflenmiştir (21). İ̈AB yapılarak malign tümör tanısı konulması, tümörün evrelemesi, cerrahi planlaması, hastaya olası risk ve komplikasyonlar hakkında daha detaylı bilgi verilmesini sağlayacaktır. Bu çalışmada, klinik muayene ve radyolojik değerlendirme sonrası parotis kitlesi saptanan tüm olgulara IIIAB önerilmiştir.

Tablo 5. Parotis kitle boyutuna göre İnce lğne Aspirasyon Biyopsisi Sonuçlarının değerlendirilmesi.

\begin{tabular}{|l|ccccc|}
\hline $\begin{array}{l}\text { Parotis bezi } \\
\text { kitle boyutu }\end{array}$ & Duyarlılık & Özgüllük & Doğruluk & PÖD & NÖD \\
\hline $\begin{array}{l}\text { Tüm gruplar } \\
\text { Alt gruplar }\end{array}$ & $\% 60$ & $\% 95.5$ & $\% 81$ & $\% 90$ & $\% 77.8$ \\
\hline $0<\leq \mathrm{cm}$ & $\% 50$ & $\% 88.9$ & $\% 76.9$ & $\% 66.7$ & $\% 80$ \\
$2<\leq 4 \mathrm{~cm}$ & $\% 50$ & $\% 100$ & $\% 83.3$ & $\% 100$ & $\% 80$ \\
$>4 \mathrm{~cm}$ & $\% 80$ & $\% 100$ & $\% 83.3$ & $\% 100$ & $\% 50$ \\
\hline
\end{tabular}

PÖD, Pozitif Öngörü Değeri; NÖD, Negatif Öngörü Değeri.

Literatürde, İ̈AB duyarlıığı \%54 ile \%92 arasında bildirilirken, özgüllük \%86 ile \%100 arasında bildirilmiştir (Tablo6). Piccioni ve ark. (22) yaptıkları çalışmada, parotis IIAAB 'in duyarlılığı \%81 ve özgüllüğünü \%99 olduğunu bildirmiştir. Lurie ve ark. (23) yaptıkları çalışmada, IIIAB 'nin duyarIılığı \%66, özgüllü̆g̈ü \%100 ve doğruluğu \%69.2 olarak bildirilmiştir. Lim ve ark. (9) yaptıkları çalışmada, duyarlılık ve özgüllük $\% 80$ ve $\% 100$ olarak bildirilmiştir. Aydoğdu ve ark. (24) yaptıkları çalışmada, duyarılıık \%75, özgüllük \%95.4, PÖD \%75, NÖD \%87.5 ve doğruluk \%85.7 olarak bildirilmiş̧tir. Yeğin ve ark. (3) tarafından yapılan çalışmada, bu oranlar sirasıyla $\% 57.2, \% 100, \% 91.4, \% 100$ ve $\% 92$ olarak bildirilmiştir. Zbaren ve ark. (10) bu oranları sırasıyla $\% 64, \% 95, \% 83, \% 87$ ve $\% 86$ olarak bildirmiştir. Özdoğan ve Özel (25) yaptıkları çalışmada, bu oranları sırasıyla \% $80, \% 99.1, \% 88.8, \% 98.3$ ve $\% 97.6$ olduğunu bildirmiştir. Bu çalışmada, IİAB testinin duyarlılı̆ı \%60, özgüllüğü $\% 95.5$, PÖD $\% 90$, NÖD \%77.8 ve doğruluk \%81 olarak saptandı. Tüm olgular parotis kitlesinin boyutuna göre üç gruba ayrıldı. Kitle boyutu $2 \mathrm{~cm}$ 'den küçük olan olgular için bu oranlar sırasıyla $\% 50, \% 88.9, \% 66.7, \% 80$ ve $\% 76.9$ idi. 
Kitle boyutu 2- $4 \mathrm{~cm}$ arasında olanlar için bu oranlar sırasıyla $\% 50, \% 100, \% 100, \% 80$ ve $\% 83.3$ idi. Kitle boyutu $4 \mathrm{~cm}$ 'den büyük olanlar için bu oranlar sırasıyla $\% 80$, $\% 100, \% 100, \% 50$ ve $\% 83.3$ idi. Literatürde kitle boyutu ile IIIAB test sonuçları arasındaki ilişkiyi açıklayan çok az çaıışma bulunmaktadır. Bu çalışma verileri değerlendirildiğinde, kitle boyutu arttıkça maligniteyi saptama ve doğru tanı koyma oranı da artmaktadır. Büyük kitlelerde, parotis benign ve malign tümör saptanma oranının artması, gereksiz cerrahileri önleyecektir. Bununla birlikte, IIIAB ile hiçbir zaman malignite kesin olarak dışlanamaz.

Tablo 6. Daha önce yapılmış olan çalışmaların değerlendirilmesi

\begin{tabular}{|l|l|l|l|l|}
\cline { 2 - 5 } \multicolumn{1}{c|}{} & Sayı & Duyarlıık & Özgüllük & Doğruluk \\
\hline Yegin (3) & 61 & 57.2 & 100 & 92 \\
\hline Aydın (7) & 60 & 94.2 & 100 & 100 \\
\hline $\begin{array}{l}\text { Mahmu- } \\
\text { dova(8) }\end{array}$ & 44 & 73 & 93 & 87 \\
\hline Lim(9) & 91 & 80 & 100 & 85.1 \\
\hline Zbaren (10) & 228 & 64 & 95 & 86 \\
\hline Fakhry (15) & 202 & 80 & 89.5 & 86.5 \\
\hline $\begin{array}{l}\text { Al-Khafaji } \\
\text { (17) }\end{array}$ & 154 & 82 & 86 & 84 \\
\hline $\begin{array}{l}\text { Stewart (18) } \\
\text { Seethala }\end{array}$ & 341 & 92 & 100 & 98 \\
\hline $\begin{array}{l}\text { (20) } \\
\text { Piccioni(22) }\end{array}$ & 176 & 81 & 99 & 97 \\
\hline $\begin{array}{l}\text { Lurie(23) } \\
\text { Aydoğdu }\end{array}$ & 52 & 66 & 100 & 69.2 \\
\hline (24) & 128 & 75 & 95.4 & 85.7 \\
\hline Aversa (26) & 310 & 83 & 100 & 97 \\
\hline $\begin{array}{l}\text { Özdamar } \\
\text { (28) }\end{array}$ & 90 & 69.6 & 93.1 & 86.4 \\
\hline Bajaj (29) & 69 & 84 & 96 & 94 \\
\hline $\begin{array}{l}\text { Günizi (30) } \\
\text { Bu çalışma }\end{array}$ & 66 & 64 & 91 & 86 \\
\hline
\end{tabular}

Schmidt ve ark. (11) tarafından yapılan, 2011 yılına kadar yapıImış olan çalışmaları değerlendiren bir meta-analiz çaIışmasında, iliAB testinin duyarlıı̆̆ $\% 80$ ve özgüllüğünü $\% 97$ olduğunu bildirmiştir. Parotis kitlelerinde IIIAB testinin duyarlılığı \%95 'den daha yüksek oranda bildiren bir çaışma bulunmamaktadır. Bunun nedeni, malignite tanısını yüksek oranda yanlış saptamasıdır. Yapılan çalışmalarda malign tümörlerin \%8-49 oranında yanlışlıkla benign patoloji olarak rapor edildiği bildirilmiştir (8-11,26,27). Bu çalışmada, IİAB sonucu negatif olan iki olgunun patolojik spesmen incelemesi sonucunda bir olgu leiomyosarkom iken, diğer olgu adenoid kistik karsinom olduğu saptandı. Parotis IIAB testinin düşük doğru tanı koymasının nedenleri arasında geniş histopatolojik tanı spektrumun olması, deneyimli bir sitopatoloğa intiyaç duyulması, İ̈AB 'yi yapan hekimin deneyimi, aspiratın alınması ve hazırlanması sırasında meydana gelen teknik sorunlar yer almaktadır $(3,4)$.
Parotis kitlelerinin IİAB tanısı, yanlış tanı ve tanısal olmayan örnek (non-diagnostik) olmak üzere iki önemli durumdan etkilenmektedir. Tanısal olmayan örnek, histopatolojik tanı için yeterli materyal alınmaması olarak tanımlanır. Deneyimsiz sitopatolog ve alınan örnekte çok sayıda farklı hücre bulunması, yanlış tanı konulmasının başıca nedenlerindendir. Tanısal olmayan örnek alınmasının nedenleri arasında, IIIAB 'nin deneyimsiz hekimler tarafından alınması, alınan materyalde nekroz ve hemorajik alanların olması, hücre içeriğinin düşük olması ve küçük kitlelerden örnek alınması sayılabilir $(3,8,11)$. Yetersiz materyal ve yanlış tanı oranı literatürde $\% 3$ ile 34 oranında bildirilmektedir $(11,28)$. Yeğin ve ark. (3) yaptıkları çalışmada, tanısal olmayan örnek (non-diagnostik) oranı \%18.1 olarak bildirilmiştir. Bu çalışmada, IIIAB sonucu 19 olguda (\%33.9) tanısal olmayan örnek olduğu saptandı.

ïAB sonuçlarının doğru yorumlanması ve yanlış tanı oranının düşürülmesi, cerrah ile sitopatolog arasındaki uyuma bağılır. Sitopatoloğa olgu hakkında önceden bilgi verilmesi ve cerrahın malignite şüphesini sitopatologla paylaşması, daha etkin ve efektif sonuçların alınmasını sağlayacaktır (2).

USG eşliğinde yapılan IIIAB test duyarılı̆ğın, görüntüleme olmadan yapılan IIIAB sonuçlarına göre daha yüksek olduğu raporlanmıştır $(29,30)$. Bajaj ve ark. (29) tarafından yapılan çalışmada, USG ile yapılan IIAB duyarılığının \%20 'den \%65 'e yükseldiğini bildirmiştir. Başka bir çalışmada, Pratap ve ark. (16) USG kullanımıyla duyarııığın \%85 'e yükseldiğini bildirmiştir. Bu çalışmada, IIIAB USG kullanılmadan yapılmıştır. Hastanemizde girişimsel radyoloji kliniğinin iş yükünün fazla olması ve USG eşliğinde IIIAB randevularının geç verilmesi, tanı koyma sürecinin uzaması nedeniyle, USG eşliğinde İ̈AB 'ler yapılamamıştır. Çalışmamızda, tanısal olmayan örnek oranııın yüksek olması, bu durumla ilişkilendirilebilir. İIAB 'nin USG eşliğinde, girişimsel radyoloji kliniğinde yapılması, testin duyarııı̆ı̆ını artıracaktır.

Çalışmamız parotis kitle boyutu ile IïAB test sonuçları arasındaki ilişkiyi incelemesi açısından değerli bir çalışma olmasına karşın, bazı limitasyonları mevcuttur. Çalışmaya alınan olgu sayısının nispeten az olması, retrospektif çaIışma olması ve IIIAB 'nin USG eşliğinde yapılmamış olması başlıca limitasyonlarındandır. Bununla birlikte, ülkemizde her hastanede girişimsel radyoloji kliniklerinin olmaması, girişimsel radyoloji kliniklerinin iş yüklerinin fazla olması nedeniyle, tanı ve tedavinin gecikmemesi için IIAB 'nin USG olmasa da deneyimli cerrahlar tarafından yapılması gerektiğini düşünüyoruz.

Sonuç olarak, bu çalışmada, parotis kitle boyutu ile IIIAB test sonuçları arasındaki ilişki değerlendirildi. Parotis kitle boyutu artıkça, IIIAB test sonuçlarının duyarlıık ve özgüllüğünün artığı saptandı. Parotis İ̇AB ile kesin tanı konulamamakla beraber, güvenli, uygulaması kolay ve ucuz bir 
işlem olması nedeniyle deneyimli hekimler tarafından uygulanması gerektiği kanaatindeyiz.

\section{Açıklamalar \\ Etik Onam: Çalışma Harran Üniversitesi Etik Kurulu 04.01.2018 tarih ve 04 nolu kararla onaylanmıştır.}

\section{Çıkar çatışması: Yazarlar tarafından bildirilen çıkar çatış- ması bulunmamaktadır.}

\section{Finansal destek: Herhangi bir kurum veya kişiden finansal destek alınmamıştır.}

\section{Kaynaklar}

1- Liu CC, Jethwa AR, Khariwala SS, Johnson J, Shin JJ. Sensitivity, Specificity, and Posttest Probability of Parotid Fine-Needle Aspiration: A Systematic Review and Meta-analysis. Otolaryngol Head Neck Surg 2016;154:9-23.

2- Loehn B, Sutton C, Jastram-Belcher J, Harton A, Anderson D, Walvekar RR. Sialadenoma papilliferum of the parotid gland: case report and review of literature. Head Neck 2013;35:74-6.

3- Yegin Y, Çelik M, Olgun B,Şimşek BM, Kayhan FT. Diagnostic value of fine needle aspiration biopsy in parotid gland neoplasm. Int J Otorhinolaryngol Head Neck Surg 2016;2(2):56-60.

4- Demir D, Akçam MT, Karakoç Ö, Öngörü Ö, Yetişer S. Diagnostic accuracy of fine needle aspirati on biopsy in head and neck masses. Kulak Burun Boğaz ve Baş Boyun Cerrahisi Dergisi 2006;5:5-11.

5- Zerpa Zerpa V, Cuesta Gonzáles MT, Agostini Porras G, Marcano Acuña M, Estellés Ferriol E, Dalmau Galofre J. Diagnostic accuracy of fine needle aspiration cytology in parotid tumours. Acta Otorrinolaringol Esp 2014;65:157-61.

6- Koç S, Eyibilen A, Aladağ I, Aksakal C. Parotis lezyonlarında ince iğne aspirasyon biyopsisinin tanısal değeri. AlBÜ İzzet Baysal Tıp Fakültesi Dergisi 2011;6:25-9.

7- Aydın S, Hardal Ü, Şanlı A, Evren C, Gül AE. Parotis bezi kitlelerinde ince iğne aspirasyon biyopsisinin yeri. Kartal Eğitim Araştırma Hastanesi Tıp Dergisi 2006;17:13-6.

8- Mahmudova R, Akyıldıs S, Midilli R, Uluöz Ü, Yavuzer A. Parotis kitlelerinde ince iğne aspirasyon biyopsisinin tanısal değeri. Ege Tıp Dergisi 2010;49:83-6.

9- Lim CM, They J, Loh KS, Chao SS, Lim LH, Tan LK. Role of fineneedle aspiration cytology in the evaluation of parotid tumours. ANZ J Surg 2007;77:742-4.

10- Zbaren P, Schar C, Hotz MA, Loosli H. Value of fine needle aspiration cytology of parotid gland masses. Laryngoscope 2001;111:198992.

11- Schmidt RL, Hall BJ, Wilson AR, Layfield LJ. A systematic review and meta-analysis of the diagnostic accuracy of fine-needle aspiration cytology for parotid gland lesions. Am J Clin Pathol 2011;136:45-59.

12- Batsakis JG, Sueige N, El-Naggar AK.Fine-needle aspiration of salivary glands: its utility and tissue effects. Ann Otol Rhinol Laryngol 1992:101:185-8.

13- Çuhruk Ç, Saatçi MR, Demireller A, Vural E. Parotis malign tümörleri hakkında gözlemlerimiz ve tedavi prensiplerimiz. Türk Otolarengoloji Arsivi 1995;33:212-22.

14- Jeong WJ, Park SJ, Cha W, Sung MW, Kim KH, Ahn SH. Fine needle aspiration of parotid tumors: diagnostic utility from a clinical perspective. J Oral Maxillofac Surg 2013;71:1278-82.

15- Fakhry N, Antonini F, Michel J, Penicaud M, Mancini J, Lagier $A$, et al. Fine-needle aspiration cytology in the management of parotid masses: evaluation of 249 patients. Eur Ann Otorhinolaryngol Head Neck Dis 2012;129:131-5.

16- Pratap R, Qayyum A, Ahmed N, Jani P, Berman LH. Ultrasoundguided core needle biopsy of parotid gland swellings. J Laryngol Otol
2009:123:449-52.

17- Al-Khafaji BM, Nestok BR, Katz RL. Fine-needle aspiration of 154 parotid masses with histologic correlation: ten-year experience at the University of Texas M. D. Anderson Cancer Center.Cancer 1998;84:153-9.

18- Stewart CJ, MacKenzie K, McGarry GW, Mowat A.. Fine-needle aspiration cytology of salivary gland: a review of 341 cases. Diagn Cytopathol 2000;22:139-46.

19- Postema RJ, van Velthuysen ML, van den Brekel MW, Balm AJ, Peterse JL.Accuracy of fine-needle aspiration cytology of salivary gland lesions in The Netherlands Cancer Institute. Head Neck 2004;26:41824.

20- Seethala RR, LiVolsi VA, Baloch ZW. Relative accuracy of fine-needle aspiration and frozen section in the diagnosis of lesions of the parotid gland. Head Neck 2005;27:217-23.

21- Lin AC, Bhattacharyya N. The utility of fine needle aspiration in parotid malignancy. Otolaryngol Head Neck Surg 2007;136:793-8.

22- Piccioni LO, Fabiano B, Gemma M, Sarandria D, Bussi M. Fineneedle aspiration cytology in the diagnosis of parotid lesions. Acta Otorhinolaryngol Ital 2011;31:1-4.

23- Lurie M, Misselevithch I, Fradis M. Diagnostic value of fine-needle aspiration from parotid gland lesions. Isr Med Assoc J 2002;4:681-3.

24-Aydoğdu I, Saltürk Z,Uyar Y,Yıldırım G,Çakır Ç,Ataç E. İnce İğne Aspirasyon Biyopsisinin Parotis Kitlelerinin Tanısındaki Yeri. Okmeydanı Tıp Dergisi 2015;31(4):175-8.

25-Özdoğan F, Özel HE. Correlation between fine needle aspiration biopsy and histopatological findings in the diagnosis of parotid tumors. J Clin Anal Med 2017;8(4): 324-6.

26- Aversa S, Ondolo C, Bollito E, Fadda G, Conticello S. Preoperative cytology in the management of parotid neoplasms. Am J Otolaryngol 2006;27:96-100.

27- Stow N, Veivers $D$, Poole A. Fine-needle aspiration cytology in the management of salivary gland tumors: an Australian experience. Ear Nose Throat J 2004;83:128-31.

28- Özdamar K, Aydın S, Altaş B, Yücebaş K, Altınay S, Öğreden Ş, Oktay MF.Parotis kitlelerinde ince iğne aspirasyon biyopsisinin önemi. KBB Uygulamaları 2015; 3(1): 20-4.

29- Bajaj Y, Singh S, Cozens N, Sharp J.Critical clinical appraisal of the role of ultrasound-guided fine-needle aspiration cytology in the management of parotid tumours. J Laryngol Otol 2005;119:289-92.

30- Günizi H, Güney K. Parotis kitlelerinde ince iğne aspirasyon biyopsisi ve histolojik bulguları arasındaki korelasyon. Şişli Etfal EAH Tıp BüIteni 2013;47(4):177-80. 